\title{
ULTRA-HIGH INTENSITY PROTON ACCELERATORS AND THEIR APPLICATIONS * CONF-970503--
}

\author{
W.T. Weng, AGS Department, Brookhaven National Laboratory, Upton, NY 11973
}

\section{Abstract}

The science and technology of proton accelerators have progressed considerably in the past three decades. Three to four orders of magnitude increase in both peak intensity and average flux have made it possible to construct high intensity proton accelerators for modern applications, such as: spallation neutron sources, kaon factory, accelerator production of tritium, energy amplifier and muon collider drivers. The accelerator design focus switched over from intensity for synchrotrons, to brightness for colliders to halos for spallation sources. An overview of this tremendous progress in both accelerator science and technology is presented, with special emphasis on the new challenges of accelerator physics issues such as: $\mathrm{H}^{-}$injection, halo formation and reduction of losses.

\section{INTRODUCTION}

The road to ultra-high intensity proton accelerators has many origins. First is the availability of high current, low emittance, high duty factor $\mathrm{H}^{+}$and $\mathrm{H}^{-}$ion sources. Second is the introduction of Radio Frequency Quadrapole (RFQ) to replace Cockcroft-Waton as effective pre-accelerator. Third is the advancement in the understanding of beam dynamics in the proton linac and the introduction of CCDTL as effective matching structure between low $\beta$ DTL and high $\beta \mathrm{CCL}$. The fourth is the development of synchrotrons to reach several tens of amperes in average current. For example, the evolution of synchrotron intensity from 1960 to the present is summarized in Fig. 1, where the numbers shown in the parenthesis refer to the rep-rate of operation.

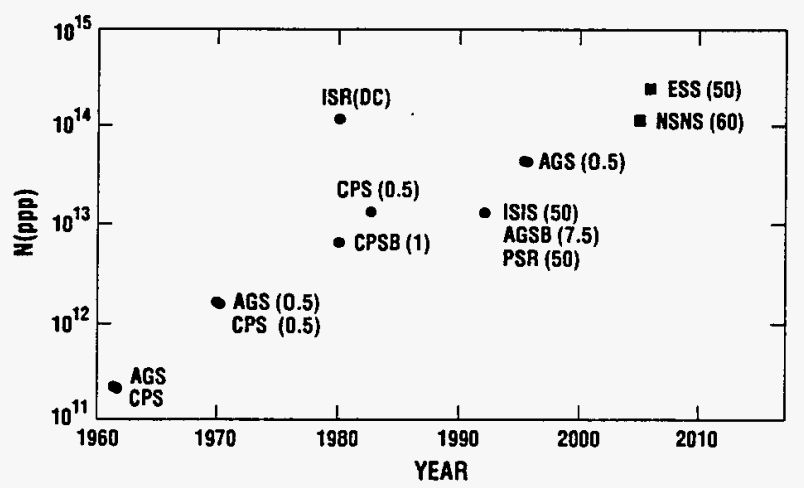

Figure 1: Evolution of synchrotron intensity.

Combined those four components together, a totally new

\footnotetext{
-Work performed under the auspices of U.S. Department of Energy.
}

picture emerges. All of a sudden, many mega watts of beam power, either in $\mathrm{CW}$ or pulsed form, becomes available. Many new ideas of how to utilize and exploit such a beam power surface.

The key developments in the accelerator science and technologies in the past thirty years will be reviewed in Sec. 2. Major new applications with high probability of been realized in the near future will be reviewed in Sec. 3 .

\section{KEY ACCELERATOR DEVELOPMENTS}

The key developments in accelerator science and technologies are summarized in Table 1. Principles and merits of each development can be found in the references given. One recent review on traditional accelerator physics issues of how to achieve high intensity on proton synchrotrons can be found in ref. [12]. More recent concerns on issues pertaining to ultra-high intensity operation are explained in the following.

Table 1: Important accelerator scientific and technological developments (1960-1997).

\begin{tabular}{|l|l|}
\hline DEVELOPMENTS & ADVANTAGES \\
\hline$H^{-}$ion sources [1] & $\begin{array}{l}\text { high current, low emittance, } \\
\text { high duty factor }\end{array}$ \\
\hline RFQ [2] & $\begin{array}{l}\text { compact, bunching, low } \\
\text { emittance }\end{array}$ \\
\hline Linac [3] & $\begin{array}{l}\text { CCDTL, S. C. linac, } \\
\text { numerical simulations }\end{array}$ \\
\hline$H^{-}$injection [4] & $\begin{array}{l}H^{\circ} \text { population, many turns } \\
\text { injection and painting }\end{array}$ \\
\hline $\begin{array}{l}\text { Resonance } \\
\text { correction [5] }\end{array}$ & $\begin{array}{l}\text { allow higher space charge } \\
\text { tune shift }\end{array}$ \\
\hline RF feedback [6] & beam loading compensation \\
\hline $\begin{array}{l}\text { Coherent } \\
\text { instabilities [7] }\end{array}$ & impedance budget, damping \\
\hline $\begin{array}{l}e-p \text { threshold [8] } \\
\text { Halo Formation [9] }\end{array}$ & $\begin{array}{l}\eta<10^{-3} \text {, electron loss } \\
\text { control, beam clearing } \\
\text { lattice effect, dynamic } \\
\text { aperture, collimation }\end{array}$ \\
\hline Beam loss control [10] & design, injection, collimation \\
\hline $\begin{array}{l}\text { Accelerator } \\
\text { operation [11] }\end{array}$ & $\begin{array}{l}\text { beam-based modeling, } \\
\text { orbit control }\end{array}$ \\
\hline
\end{tabular}

\section{$2.1 H^{-}$Injection}

In modern day application, for the injection of proton beam from a linac into a synchrotron, a $\mathrm{H}^{-}$beam is prefered. 
This is due to the foil-stripping process allows the repetitive stacking of incoming beam into the same phase space area which is impossible with a $\mathrm{H}^{+}$beam. Typical foil used is carbon or graphite foil of about 200 to $400 \mu \mathrm{g} / \mathrm{cm}^{2}$. The stripping efficiency ranges from $98 \%$ to $99.5 \%$. The critical issues faced in this process is the foil temperature, the collection of $\mathrm{H}^{-}, \mathrm{H}^{\circ}$ and electrons. In the event that beam losses in the order of few $10^{-4}$ have to be realized, careful identification of $H^{\circ}$ population in various excited states is necessary [4]. Another important design concern is the emittance blow up due to multiple traverse of foil which has to be minimized.

\section{2 e-p Instability [8]}

There are many ways electrons can be generated in a synchrotron. For example, they can be generated at stripping foil, by residual gas ionization, or by secondary electron emission from the wall. Experiences showed that if the population of electrons reaches certain level, characterized by the neutralization coefficient, $\eta_{e}$ defined to be the ratio of electron to proton, the proton beam can become unstable due to coherent motion excited by the presence of electrons.

Ways to eliminate $e-p$ instability include better vacuum, collect electrons at stripping foil location, TiN coating of vacuum chamber, and clearing electrodes. In the event that the instability does occur, an active damping system can be provided to suppress the instability.

\subsection{Halo Formation}

It has been found that the large amplitude particle can interact with the core particles to move either closer to the center or away from the center $[9,13,14,15]$. This process can be understood by an envelop oscillation created by the mismatch between the beam shape and the lattice of the focusing channels. A particle in the halo region tends to be driven away in such a mismatched focusing channel. Although the smaller amplitude particles stay close to the stable fixed point in the center, the larger amplitude particles can drift away following the multiple islands as show in Fig. 2 [14]. The crucial questions now, are first how far the islands can extend away from the center, what are the dynamical nature of the islands, and when the chaotic motion will set in. Those are all important questions to be answered by any new high power accelerators. It can happen both in the linac and in the circular rings.

A thorough understanding of the halo dynamics as function of mismatch, power supply ripple, space charge tune shift, and the lattice structure, etc., is necessary to be able to estimate the degree of beam losses with confidence.

Assuming Gaussian distribution, the development of proton synchrotron and main attention of accelerator physics in the past 40 years can be roughly classified into three period. Period 1 located roughly between 1960 to 1975 when the total intensity for fixed target research was a major concern. The figure of merit in this period is the

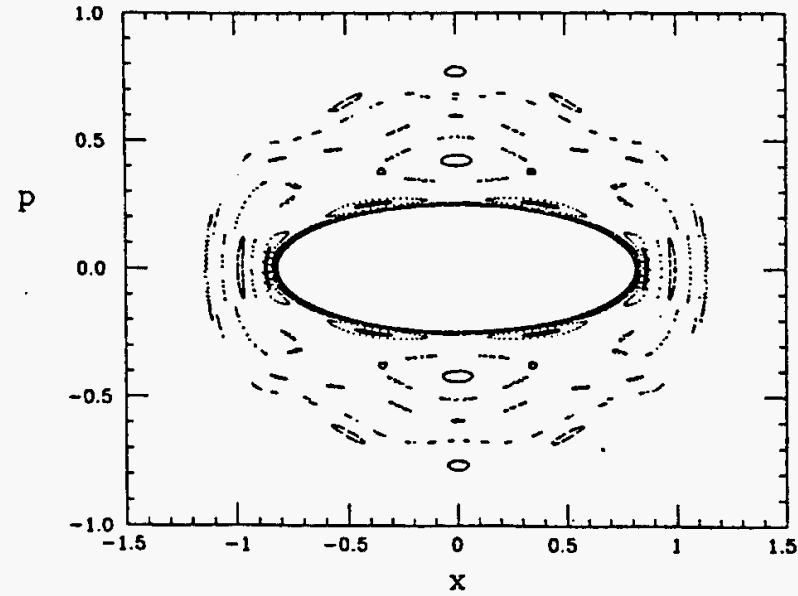

Figure 2: The Poincare surface of section in particle phase space from particle-core interaction [14].

total intensity,

$$
N=\int_{-2.5 \sigma}^{2.5 \sigma} f(z) d z
$$

Period 2 located roughly between 1970 to 1990 when the brightness for colliding beam research was a major concern. The corresponding figure of merit is the brightness [16], $B=N / \sigma$. Period 3 started from 1990 and could well extend to 2010 when the loss of the halo particles is a major concern. The corresponding figure of merit will be the population and dynamics of the halo particles,

$$
H=2 \int_{4 \sigma}^{\infty} f(z) d y .
$$

\subsection{Beam Loss Control}

Typical beam losses of existing low power proton synchrotron is in the order of a few percent. Let us use the AGS and the proposed NSNS ring as example. The relevant beam parameters are summarized in Table 2 .

It can be clearly seen that $1 \%$ loss of the NSNS ring is equivalent to the entire flux of the AGS beam. Such a situation is totally unacceptable. That is why the design criterion for next generation spallation neutron sources is kept in the order of a few $10^{-4}$ to allow for hands-on maintenance after a long operation period.

To contain those particles inadvertently migrating toward the wall, after all careful considerations and provisions, a collimator system has to be designed to catch the bulk of them before hitting the wall. For example, for the

Table 2: AGS and NSNS parameters.

\begin{tabular}{|c|c|c|}
\hline & AGS [12] & NSNS [17] \\
\hline Proton Intensity & $6 \times 10^{13} \mathrm{ppp}$ & $10^{14} \mathrm{ppp}$ \\
\hline Rep-Rate & 0.5 & 60 \\
\hline Flux & $3 \times 10^{13} \mathrm{pps}$ & $6 \times 10^{15} \mathrm{pps}$ \\
\hline Loss 0f $1 \%$ & $3 \times 10^{11} \mathrm{pps}$ & $6 \times 10^{13} \mathrm{pps}$ \\
\hline
\end{tabular}




\section{DISCLAIMER}

This report was prepared as an account of work sponsored by an agency of the United States Government. Neither the United States Government nor any agency thereof, nor any of their employees, make any warranty, express or implied, or assumes any legal liability or responsibility for the accuracy, completeness, or usefulness of any information, apparatus, product, or process disclosed, or represents that its use would not infringe privately owned rights. Reference herein to any specific commercial product, process, or service by trade name, trademark, manufacturer, or otherwise does not necessarily constitute or imply its endorsement, recommendation, or favoring by the United States Government or any agency thereof. The views and opinions of authors expressed herein do not necessarily state or reflect those of the United States Government or any agency thereof. 
NSNS four collimators, $3.2 \mathrm{~m}$ each, enclosing a $4 \pi$ solid angle around the source point and stuffed with segmented material to capture all secondary particles generated by the incident protons will be provided to reduce the radiation effects by a factor of 100 . This way, most of uncontrolled losses will occur at the collimator, leaving ring components relatively intact for reliable operation [18].

\subsection{Accelerator Operation [11]}

For high reliability and low loss operation of any high power accelerators, the performance standard of typical 3rd generation synchrotron radiation source should be achieved. Those accelerators routinely achieve orbit stability in the order of tens of microns and the measurement of betatron function to better than a few percent. To achieve such a performance, a well-thought out plan of diagnostic devices and realistic computer model-based operation have to be implemented.

\section{EXAMPLE OF APPLICATIONS}

By the early 1990 's, there were a realization that the high intensity proton accelerator technology had come of age and a wide range of new demands from scientific, industrial, and governmental concerns can be met by the availability of this new technology. Listed in Table 3 are five interesting and promising applications of such ultra-high intensity proton accelerators.

\subsection{Accelerator Production of Tritium (APT) [19]}

The strategic reserve of Tritium could diminish due to natural decay of such material. Traditionally Tritium was produced by the reactors which are now perceived to be potentially unsafe and pollution-prone. The alternative is to use high power $\mathrm{CW}$ proton linac to produce sufficient number of neutrons for the production of Tritium.

The proposal under conceptual design at LANL uses a super-conducting proton linac of $1.7 \mathrm{GeV}$ with $100 \mathrm{~mA}$ beam delivering $170 \mathrm{MW}$ power to the target. The technical challenges of this project is clearly in the attainment

Table 3: Examples of possible applications of ultra-high intensity proton accelerators.

\begin{tabular}{|c|c|c|c|c|}
\hline Applications & $\begin{array}{c}\text { Beam } \\
\text { Energy } \\
(\mathrm{GeV})\end{array}$ & $\begin{array}{c}\text { Beam } \\
\text { Current } \\
(\mathrm{mA})\end{array}$ & $\begin{array}{c}\text { Rep- } \\
\text { Rate } \\
(\mathrm{Hz})\end{array}$ & $\begin{array}{c}\text { Average } \\
\text { Beam } \\
\text { Power } \\
(\mathrm{MW})\end{array}$ \\
\hline APT [19] & $1.3-1.8$ & 100 & $\mathrm{CW}$ & $130-180$ \\
\hline $\begin{array}{c}\text { Nuclear } \\
\text { Transmutation } \\
{[20,21]}\end{array}$ & 1.5 & 16 & $\mathrm{CW}$ & 25 \\
\hline $\begin{array}{c}\text { Energy } \\
\text { Amplifier [22] }\end{array}$ & 1.0 & 12.5 & $\mathrm{CW}$ & 12.5 \\
\hline SNS [17,23] & $1.0-1.5$ & $0.5-3.0$ & $\sim 50$ & $1-3$ \\
\hline $\begin{array}{c}\mu \text {-collider } \\
\text { Driver [24] }\end{array}$ & 30 & 0.25 & 15 & 7.0 \\
\hline
\end{tabular}

of high current, minimization of particle losses, and the design of target system. To safely and reliably operate a linac at such high current requires every care and ingenuity from the accelerator designers. The Las Alamos team payed special attentions to the design of RFQ to bunch and pre-accelerate the beam with very good emittance preservation, introduced CCDTL section to improve in matching between DTL and CCL, allowed for high "rms aperture ratios" the radio of transverse aperture to rms beam size and longitudinal bucket width to rms beam length. Typically, in the transverse dimension the rms aperture ratios of at least 10 are provided. Furthermore, the design is simulated in a fully nonlinear, 3-D particle-in-cell simulation code, using a large number of particles, and including various errors given by engineering tolerances. These runs have to show a well-matched beam, adequate aperture factors, and no particle losses before they can considered to be acceptable. The whole design procedure is a combination of beam dynamics, engineering configuration, numerical simulation, and finally cost optimization. Halo dynamics and associated beam losses have been thoroughly studied and measured in some occasions $[3,9]$ to ensure that beam losses of less than $\mathrm{nA} \mathrm{A} / \mathrm{m}$ is achieved for "hands-on" maintenance and component reliability.

Super-conducting technology has been applied to accelerator through the CEBAF project for electron linac. The successful implementation of super-conducting technology to the APT will be a major breakthrough and will result in substantial cost saving for future operations. The U.S. Department of Energy will make final technological choice of APT in the fall of 1998.

\subsection{Nuclear Transmutation [20, 21]}

The nuclear power plants have been used to provide power for the past 50 years. One of the byproducts of the processes is the tremendous amount of long-lived nuclear waste. For environmental concern, those nuclear waste should be safely disposed. For the long term future of nuclear power, until the waste problem is solved, public opposition will undoubtedly continue. The required solution must reduce both the volume of existing waste and its radioactivity, so the waste becomes benign by the end of period over which a society might be able to retain control, say a few hundred years.

The ideas of breaking down long-lived radio-active product from nuclear power plants has been surfaced a while ago [20]. However, the need of fast neutron flux in the order of $10^{15}-10^{16}$ neutron $/ \mathrm{cm}^{2} / \mathrm{sec}$ was not readily available then. It took twenty years intensively R\&D efforts to bring the accelerator technology closer to the requirements of viable and efficient application in this area. One of the original example suggested and tested is to convert $T c^{99}$ of half life $2.1 \times 10^{5}$ years by neutron capture to $T c^{100}$ which can quickly through $\beta$-decay (half life $15.8 \mathrm{sec}$ ) become $R u^{100}$ which is stable. Another example are minor actinides, such as, $N p^{237}$ or $A m^{241}$ which have half life of $\sim 1000$ years by $\alpha$-emission. Those can be fissioned by fast neutron to 
become fission products of half life around a few years.

The soon-to-be-approved project of nuclear transmutation is the OMEGA project at JAERI [21]. As shown in Table 3, OMEGA requires a super-conducting linac of $1.5 \mathrm{GeV}, 16 \mathrm{~mA}$ delivering average power of $\sim 25 \mathrm{MW}$. The major concerns of how to provide a reliable, high power proton source is the same as that required by APT, although the end use is some what different.

\subsection{Energy Amplifier (EA)}

The need of an industrialized society to have reliable supply of inexpensive power source can never be overemphasized. However, the continuous application of nuclear power is hampered by both the safety and waste treatment problems. The two challenging problems can be substantially resolved by the proposal of the Energy Amplifier by C. Rubbia [22].

There are two important key concepts to modify nuclear reactors for new applications. First is to replace the $\mathrm{UO}_{2}$ with $\mathrm{ThO}_{2}$ as the core fuel whose production of neutron will stay sub-critical for sustained chain reaction. Secondly, the required additional fast neutrons will be provided by spallation neutron generated by high intensity proton accelerator. In the CERN proposal, the final stage of proton accelerator is a cyclotron of $1.0 \mathrm{GeV}$ with expected beam power of about $12.5 \mathrm{MW}$. Through this arrangement, the fuel is used much more efficiently. For example, the power obtained from $780 \mathrm{~kg}$ of Thorium is roughly the same as the one from 200 tons of native Uranium. Furthermore, the probability of a critical accident is suppressed since the device operates at all times far away from it. Spontaneous convective cooling by the surrounding air makes a "meltdown" leak impossible. In case of any incident, the accelerator can be shut down in a matter of a few micro-seconds, a much responsive operation than traditional Pressurized Water Reactor (PWR).

One more addition advantage is the life time of typical spent fuel from the EA facility is about 700 years which is many orders of magnitude lower than those products from PWR. The waste treatment becomes easier and more reliable.

\subsection{Spallation Neutron Sources (SNS)}

The potential of using neutron to probe material structure was immediately recognized when copious amount of neutrons became available in the 1930's. In the advent of highintensity proton accelerators, the accelerator-driven spallation neutron sources became available in the 1980's. Notable examples are the ISIS at Rutherford, PSR at LANL, IPNS at ANL, and KENS at KEK.

By the 1990's, it became evident that the need of neutron sources is increasing and the availability of traditional neutron sources from nuclear reactors is decreasing. Many advances in industrial society are driven by new technologies, and most of these new technologies depend on the development of new materials such as high-strength ceram- ics and composited, magnetic and electro-optic materials, or new high transition temperature super-conductors. The approach to developing many of these materials requires understanding their interactions at atomic level and relating these interactions to macroscopic properties. This usually requires the use of large facilities such as synchrotron radiation sources and neutron sources. Neutrons have several unique advantages for determining the structure and dynamics of a wide range of materials. This is why the demand of neutrons has increased so rapidly and spread to so many fields of science in the last 20 years, and why there is a need for new spallation neutron sources.

Shown in Fig. 3 is the evolution of average neutron fluxes over the years from both the reactor sources and the SNS's. The advances of the accelerator technologies played a major role in making the high flux SNS possible. To meet the increasing demand of high flux neutron sources, there is a surge of new proposals for pulsed spallation neutron source in the few MW range all over the world. In Table 4, we list the parameters of three most powerful SNS in operation and four proposals for new SNS. At this moment, the probability of any of the proposal been approved in the next few years ranges from 80 to $20 \%$. It would be very interesting to see which one actually get built and when.

All the four new proposals for SNS provide pulsed proton beam of $\sim 1 \mu \mathrm{sec}$ long and spaced by $\sim 20-50 \mathrm{msec}$. Pulsed neutron beam is essential for studies of dynamical properties of materials and cell samples by time of flight technique. The signal to background / noise ratio is much enhanced due to the peak intensity of shout pulse.

For such a short pulse facility, an accumulator ring or rapid cycling synchrotron is needed to compress the $\sim 1 \mathrm{msec}$ linac beam into less than $1 \mu \mathrm{sec}$ by $H^{-}$charge exchange injection mechanism over $\sim 1000$ turns. The modern choice is to use a liquid mercury target for the ease of design of cooling and long life time. Typical spallation process can generate more than 50 neutrons per incident proton. Complete description of various SNS can be found in references $[17,23,29]$. The accumulator ring design of the NSNS project is given in reference [30]. Currently NSNS is planned to start construction in 1999 and be completed

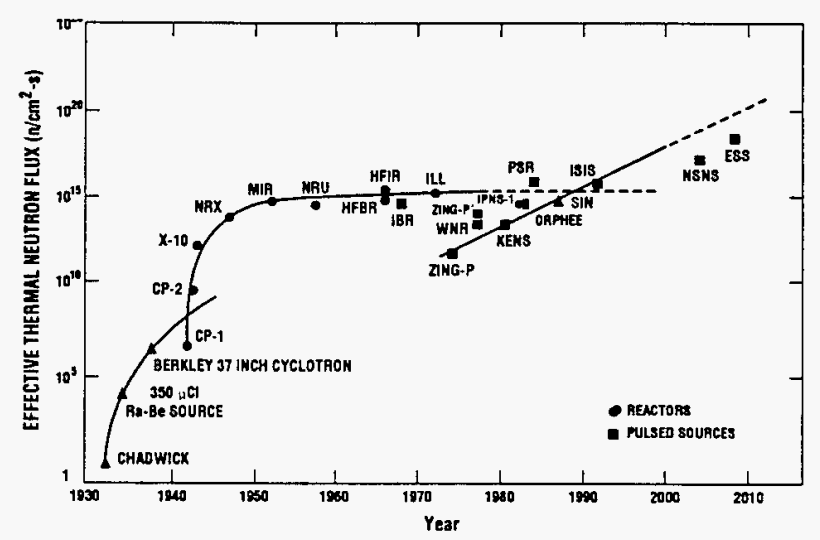

Figure 3: The evolution of average neutron fluxes. 
Table 4: Design parameters of spallation neutron sources.

\begin{tabular}{|c|c|c|c|c|}
\hline Name & $\begin{array}{c}\text { Proton } \\
\text { Energy } \\
(\mathrm{GeV})\end{array}$ & $\begin{array}{c}\text { Proton } \\
\text { Intensity } \\
(\mathrm{ppp})\end{array}$ & $\begin{array}{c}\text { Rep- } \\
\text { Rate }\end{array}$ & $\begin{array}{c}\text { Average } \\
\text { Beam } \\
\text { Power } \\
(\mathrm{MW})\end{array}$ \\
\hline \hline \multicolumn{5}{|c|}{ Existing Facilities } \\
\hline $\begin{array}{c}\text { LANSCE } \\
{[25]}\end{array}$ & 0.8 & $2.3 \times 10^{13}$ & 20 & 0.07 \\
\hline ISIS[26] & 0.8 & $2.5 \times 10^{13}$ & 50 & 0.2 \\
\hline SINQ[27] & 0.59 & $1.5 \mathrm{~mA}$ & $\mathrm{CW}$ & 1.0 \\
\hline \hline \multicolumn{5}{|c|}{ Proposed Facilities } \\
\hline JAERI[28] & 1.5 & $2.8 \times 10^{14}$ & 50 & 2.7 \\
\hline JHF[29] & 3.0 & $5.0 \times 10^{13}$ & 25 & 0.6 \\
\hline NSNS[17] & 1.0 & $1.0 \times 10^{14}$ & 60 & 1.0 \\
\hline ESS[23] & 1.334 & $2.3 \times 10^{14}$ & 50 & 2.5 \\
\hline
\end{tabular}

in 2005. Upgrades to $2 \mathrm{MW}$ and eventually to $4 \mathrm{MW}$ can be implemented when fund is available [17].

From the above brief description, it is evident that all those new applications require new performance levels from both the accelerators and the target systems. it is such a ground breaking challenges and their potential pay-offs in the acquisition of new knowledge and contributions to societal needs, makes our field so interesting and rewarding.

\section{ACKNOWLEDGMENTS}

The author would like to thank for the information and presentation materials received from the following individuals: B. Appleton, G. Bauer, J. Browne, I. Gardner, J. M. Lagniel, S. Y. Lee, Y. Mori, T. Mukaiyama, G. Rees, J. Staples and $\mathrm{N}$. Watanabe.

\section{REFERENCES}

[1] Eds L. Schroeder, K. Leung and J. Alonso, Proceedings of the Workshop on Ion Source Issues Relevant to a Pulsed Spallation Neutron Source, LBL-36347, October, 1994.

[2] M. Weiss, 'Radio-Frequency Quadrupole', CERN Accelerator School Proc., CERN 95-06, p.959, November, 1995.

[3] T.P. Wangler, 'New High-Power Linacs and Beam Physics Issues', these proceedings.

[4] M.S. Galley et al., 'Mesurement of $H^{-}, H^{\circ}$, and $H^{+}$yields produced by foil stripping of $800 \mathrm{MeV} H^{-}$ions', Phys. Rev. A. Vol.53, p.3201, May, 1996.

[5] C. Gardner et al., 'Observation of Correction of Resonance Stopbands in the AGS Booster', Proc. of PAC'93, p.3633.

[6] J.M. Brennan, 'The Upgraded RF System for the AGS and High Intensity Proton Beams', Proc. of PAC'95, p.1489, May, 1995.

[7] J. Gareyte, 'Beam Observation and the Nature of Instabilities', AIP Conf. Proc. No.184, p.343-429, New York, 1989.

[8] D. Neuffer et al., 'Observation of a Fast Transverse Instability in the PSR', Nucl. Inst. \& Methods, A321, p.1-12, 1992.

M. Plum et al., 'Experimental Evidence for the Las Alamos Proton Storage Ring Beam Instability', these proceedings.
[9] R.A. Jameson, 'Self-Consistent Beam Halo Studies and Halo Diagnostic Development', Frontiers of Accelerator Technology, World Scientific, p.530, November, 1994.

[10] P.E. Gear, 'Beam Induced Radiation Problems and cures', Proc. of EPAC'96, p.225, Sitges, Spain, June, 1996.

[11] J. Corbett and C. Wermelskirchen, 'Accelerator Controls and Modeling', Synchrotron Radiation Sources, ed. H. Winick, World Scientific, p.215, November, 1994.

[12] W.T. Weng, 'Performance and Measurements of the AGS and Booster Beams', AIP Conf. Proc. No.377, p.145, Bloomington, IN, Oct. 10-13, 1995.

[13] J-M. Lagniel, 'Halos and Chaos on Space-Charge Dominated Beams', Proc. of EPAC'96, p.163, Sitges, Spain, 1996.

[14] S.Y. Lee and A. Riabko, 'Envelop Hamiltonian of an Intense Charged-Particle Beam in Periodic Solenoidal Fields', Phys. Rev. E, Vol.51, Feb., 1995.

[15] G. Haonat, 'Experimental Results on Beam Halo', these proceedings.

[16] S. Machida, 'Space-Charge Effects in Low-Energy Proton Synchrotrons', Nucl. Inst. \& Methods, A309, p.43-59, 1991.

[17] B.R. Appleton, 'The National Spallation Neutron Source (NSNS) Project', these proceedings.

[18] H. Ludewig, S. Mughabghab and M. Todosow, 'NSNS ring system design study, collimation and shielding', BNL/NSNS Tech. Note \#5, November, 1996.

[19] W. Lisowski, 'The Accelerator production of Tritium (APT) Project', these proceedings.

[20] H. Takahashi, N. Mizov and M. Steinberg, 'Use of Linear Accelerator for Incinerating the Fission Produce of $\mathrm{CS}^{137}$ and $\mathrm{Sr}^{90}$, Int. Conf. on Nucl. Waste Transmutation, Austin, USA, July 22-24, 1980.

[21] S. Saito, 'Research and Development program on Accelerator-driven Transmutation at JAERI', Proc. of 2nd Int. Conf. on Accelerator-driven Transmutation Technology and Applications, p.52, Kalmar, Sweden, 1996.

[22] C. Rubbia et al., 'Conceptual Design of a Fast Neutron Operated High Power Energy Amplifier', CERN/AT/95-44, 1995.

[23] I. Gargner et al., 'Status of the European Spallation Source Design Study', these proceedings.

[24] B. Palmer, 'Progress on $\mu^{+} \mu^{-}$Colliders', these proceedings.

[25] R.J. Macek et al., 'Overview of Progress on the LANSCE Accelerator and Target Facilities Improvement Program', these proceedings.

[26] M.R. Harold et al., 'A Possible Upgrade for ISIS', these proceedings.

[27] G.S. Bauer et al., 'Commissioning of the IMW spallation Neutron Source', these proceedings.

[28] T. Mukaiyama, 'Neutron Science Project at JAERI', NSNS User's Workshop, Oct. 1996.

[29] Y. Mori, 'The Japanese Hadron Facility', these proceedings.

[30] W.T. Weng et al., 'Accumulator Ring Design for the NSNS Project', these proceedings. 
M97008958

$\frac{\text { Report Number (14) BNL--63753 }}{\text { CONE-970503-- }}$

Publ. Date (11) 199708

Sponsor Code (18) DOEIER, XF

UC Category (19) $4 C-4 / 4, D O E / E R$

DOE 